\title{
Chikungunya arthritis: an emerging rheumatologic problem
}

\section{Introduction}

Chikungunya virus (CHIKV) is an alphavirus that belongs to the Togaviridae family, transmitted primarily by the bite of the mosquito Aedes aegypti. Although occurrence of CHIK outbreaks has been sporadically reported in medical literature, recent description of autochthonous cases in Europe and in United States, increased the interest in the disease [1].

For the rheumatologist, the main interest in the disease is the possibility of progressing with chronic debilitating arthritis. By the way, in the Makonde language of Tanzania, where the disease was first described, chikungunya means "that which bends up", because of intensity of the pain, in a clear reference to the musculoskeletal involvement of the disease. From the public health point of view, the disease burden can be high, with an estimated cost of Chikungunya outbreaks in the Americas around US\$185 billion, which is associated with a loss of 23.8 million disability adjusted life years (DALYs) [2].

Despite the recent interest in the disease, some questions are still pending: how worried should we be about CHIK? What are the chances of dealing with it as a doctor, or even as a patient? The answers to these questions are: It depends on where you live ("geographic distribution") and on who you are ("Risk factors for chronification").

The first step to understand CHIK virus infection is learning about its characteristics and how to recognize it.

\section{Clinical and laboratory features}

The clinical picture depends on the stage of the disease. The incubation period takes 4 to 7 days, followed by an acute phase that can last 3 weeks, followed by a post-acute period $\left(2^{\text {nd }}\right.$ and $3^{\text {rd }}$ months), and finally by the chronic stage ( $>3$ months) [3]. Table 1 shows the most typical presentation in each phase.

The most frequently described laboratory abnormalities include pancytopenia (anemia, moderate thrombocytopenia and leukopenia with marked lymphopenia), increased liver enzymes, creatinine, creatine kinase, and hypocalcemia.

The choice of diagnostic tests depends on the time elapsed since the onset of symptoms. In the early phase of infection (first week) viral

\section{Fernando Antonio Glasner da Rocha Araujo*}

Associate Professor, Department of Internal Medicine, federal university of Bahia, Brazil

*Author for correspondence: faraujo.br@hotmail.com

\begin{tabular}{|c|c|c|c|}
\hline Stage & Acute & Post-acute & Chronic \\
\hline Duration & First month & $2^{\text {nd }}$ and $3^{\text {rd }}$ months & $>3$ months \\
\hline \%patients & $87 \%$ (13\% asymptomatic) & About $50 \%$ & $\begin{array}{l}\text { Variable (see } \\
\text { "Chronic } \\
\text { rheumatism") }\end{array}$ \\
\hline $\begin{array}{l}\text { Systemic } \\
\text { features }\end{array}$ & $\begin{array}{c}\text { High fever, headache, myalgia, back pain, } \\
\text { macular to maculopapular rash, sometimes } \\
\text { with cutaneous pruritus (foot arch) } \\
\text { and edema of the face and extremities, } \\
\text { polyadenopathies; followed by asthenia and } \\
\text { anorexia. }\end{array}$ & $\begin{array}{l}\text { Worsening of asthenia and } \\
\text { neuropsychological disorders } \\
\text { (anxiety, depression, memory } \\
\text { problems) }\end{array}$ & \\
\hline $\begin{array}{c}\text { Articular } \\
\text { presentation }\end{array}$ & $\begin{array}{l}\text { Arthritis/arthralgia mainly in extremities } \\
\text { (wrist, ankles and phalanges) }\end{array}$ & $\begin{array}{l}\text { Persistence of arthritis, now } \\
\text { with periarticular involvement } \\
\text { (tenosynovitis, tendinitis } \\
\text { enthesitis, bursitis, capsulitis } \\
\text { and periostitis) }\end{array}$ & $\begin{array}{c}\text { Persistence or } \\
\text { return of symptoms } \\
\text { of post-acute stage. } \\
\text { Manifest as CIR or } \\
\text { MSD. }\end{array}$ \\
\hline
\end{tabular}


detection by molecular tests is the recommended test sequences [4]. From day 5, the serological tests for detection of $\operatorname{IgM}$ antibodies can be used, while $\operatorname{IgG}$ antibodies appear after 1 to 2 weeks of disease. Serological tests are subject to false-negatives, due to the formation of cryoprecipitates, and false-positives by crossreaction [5]. In addition, IgM antibodies can remain positive for several months, and its detection not necessarily means a recent infection [6].

\section{Geographic distribution}

The geographic distribution of CHIKV corresponds to the area of action of its vectors, and the type and speed of transmission depend on the virus strain. Two strains of the virus were initially described:

- The original strain (West African cluster) circulated between primates, was transmitted by forest-dwelling mosquitoes (Aedes furcifer and Aedes taylori), with only sporadic cases in humans; and

- The Asian strain, transmitted to humans by peri-domiciliary mosquitoes (mainly Aedes aegypti), and responsible for urban focal outbreaks. In 2005 there was a mutation of the virus (strain A226VCHIKV) that facilitated its transmission by Aedes albopictus, and led to a change in the pattern of transmission with explosive outbreaks, on Reunion Island (2005-
2006), and in India (2006) [4].

The virus spread to the Americas by the end of 2013, from an outbreak in the Caribbean [7]. Today it is present in all continents, especially in the tropical and subtropical areas of the planet (Figure 1) [8].

In theory, you are more likely to get involved with the disease if you live in one of these areas. On the other hand, living in an area that has already experienced an outbreak of the disease may be protective, as infected patients develop permanent immunity, limiting the potential of new outbreaks. Nevertheless, outbreaks may occur again once a large enough proportion of susceptible individuals is present, or when the mutant virus circulates, increasing the likelihood of transmission by Aedes albopictus, in areas where this vector is more prevalent than Aedes aegypti (Figure 2) [9].

In the specific case of the United States, although sporadic cases have been registered in almost all American states, autochthonous cases have only been described in Florida, Puerto Rico, and the Virgin Islands [1]. However, most Americans living in areas covered by mosquito vectors do not have immunity to the virus and are susceptible to the disease.

\section{Chronic rheumatism}

Once severe acute forms of encephalitis and cases of death in debilitated patients are rare complications of CHIKV, the main concern about

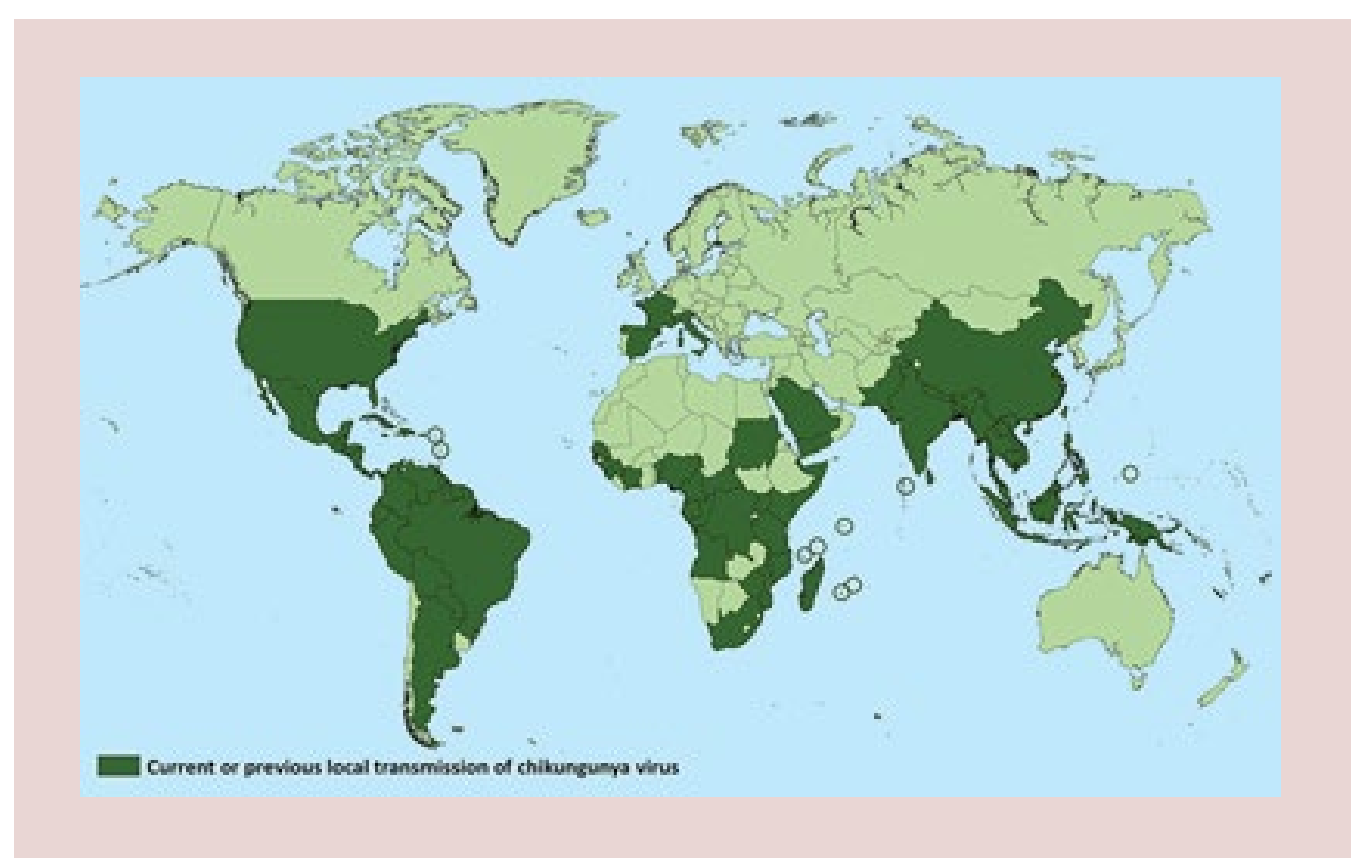

Figure 1. Countries and territories where chikungunya cases have been reported. 


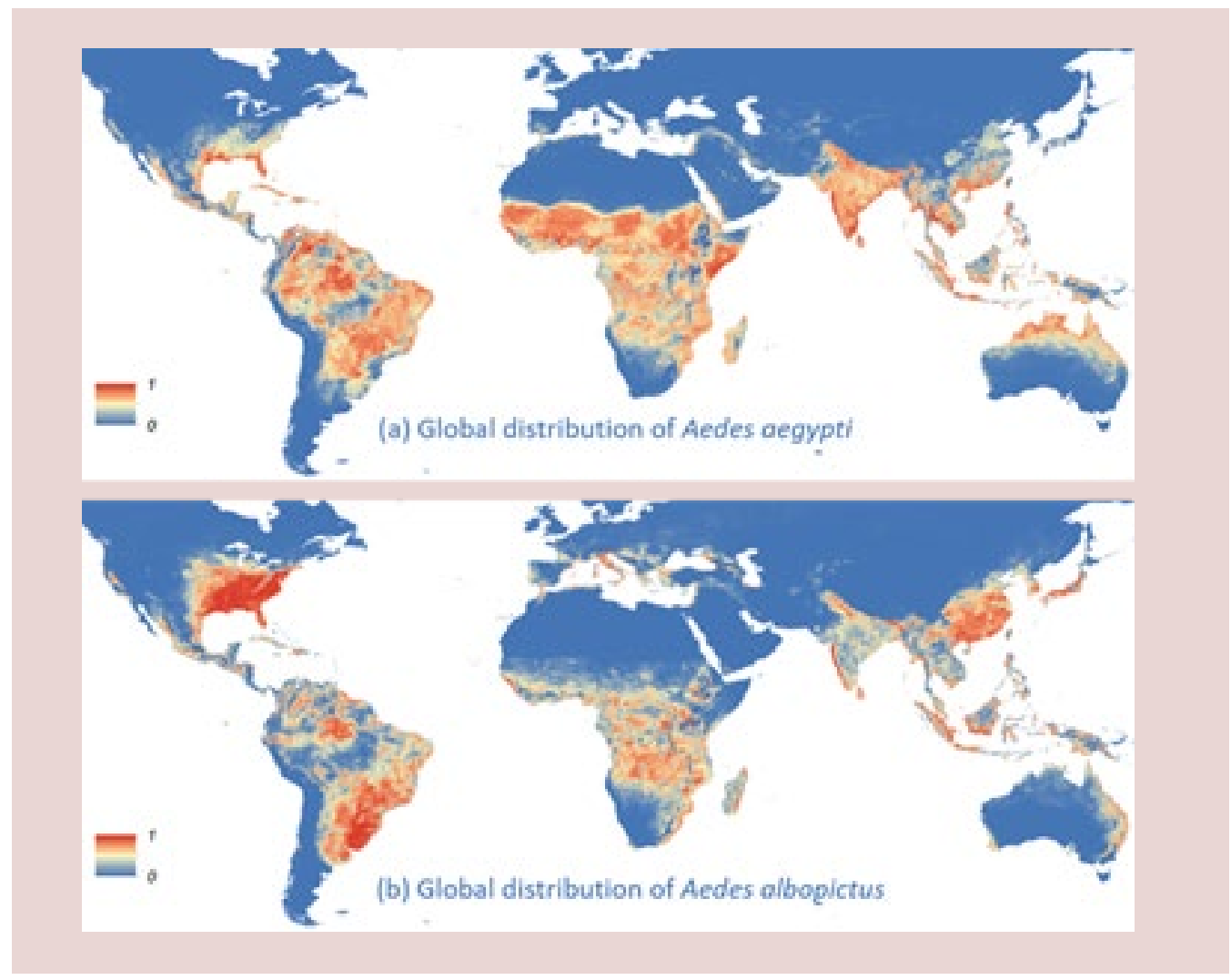

Figure 2. Global distribution of (a) Aedes aegypti (b) Aedes albopictus.

CHIKV infection is the frequent occurrence of chronic and debilitating joint inflammation. The chronic stage of the disease can be characterized by a frequent and unspecific form of general musculoskeletal disorders (MSD), or a more severe form called "post-chikungunya chronic inflammatory rheumatism” (CHIK-CIR).

CHIK-CIR is characterized by persistent mono or oligoarthritis, undifferentiated polyarthritis, or meet criteria for Rheumatoid Arthritis or Spondyloarhtritis (mainly peripheral) [3]. MSD refers to persistent or relapsing joint pain, with no associated synovitis. It is more common, and less debilitating than CHIK-CIR.

The prevalence of persistent joint disease varies among the different studies. In a meta-analysis published in 2016, that included 18 studies and 5702 patients, about $25 \%$ of patients developed CHIK-CIR (arthritis, arthralgia, fibromyalgia, frozen shoulder or plantar fasciitis) and 14\% had persistent arthritis (or spondylitis). The prevalence of chronic rheumatic complaints was even higher in the studies with a longer duration $(32.1 \%)$ or with a greater number of patients (34.1\%) [10]. The numbers are similar to those published in more recent series. Chang et al. also found a prevalence of $25 \%$ of persistent joint symptoms in a group of 485 Colombian patients followed by 20 months [11]. Among the 173 patients followed up by Essackjee et al. [12], 136 $(78.6 \%)$ presented musculoskeletal symptoms 37.5 months after infection.

\section{Risk factors for chronification}

In a recent publication, van Aalst et al. [13], reviewed 37 studies, with follow-up period between 1.5 and 72 months, to define the risk factors for persistence of joint pain, alopecia or depression. Female gender and older age (at least $>35$ years) were the associated factors.

Gerardin et al. [14], identified age $>45$ years, severe rheumatic involvement (fever, at least six joints plus four other symptoms) at presentation and CHIKV-specific IgG titers as the main risk factors for relapsing or lingering rheumatic manifestations. The association between chronicity, more advanced age and severity of the initial presentation was also reported in Mexican and Indian patients $[15,16]$.

Among the cases of Chang et al. chronification was associated with higher education, initial symptoms of headache or knee pain, and more aggressive acute disease (missed work, normal activities affected, more than 3 days of initial 
symptoms, and more than 3 weeks of initial joint pain) [11].

In conclusion, for a doctor practicing medicine in the vast global areas covered by vector mosquitoes and that takes care for female patients over the age of 40 , it is advisable to include chikungunya among your diagnostic possibilities and keep up to date on the recommended treatment.

\section{References}

1. CDC - Centers for Disease Control and Prevention. Laboratory-confirmed chikungunya virus disease cases reported to ArboNET by state. Chikungunya Virus: Geographic Distribution. https://www.cdc.gov/ chikungunya/pdfs/2014Table1_final.pdf. Published 2014. Accessed June 6, 2018.

2. Bloch D. The Cost And Burden Of Chikungunya In The Americas. 2016. http://elischolar.library.yale.edu/ ysphtdl/1022.

3. Simon F, Javelle E, Cabie A et al. French guidelines for the management of chikungunya (acute and persistent presentations). Med. Mal. Infect. 45(7), 243-263 (2015).

4. Simon F, Javelle E, Oliver $\mathrm{M}$ et al. Chikungunya virus infection. Curr. Infect. Dis. Rep. 13(3), 218-228 (2011).

5. Oliver M, Grandadam M, Marimoutou C et al. Persisting mixed cryoglobulinemia in Chikungunya infection. PLoS. Negl. Trop. Dis. 3(2), e374 (2009).

6. Prince HE, Seaton BL, Matud JL et al. Chikungunya virus RNA and antibody testing at a National Reference Laboratory since the emergence of Chikungunya virus in the Americas. Clin. Vaccine. Immunol. 22(3), 291297 (2015).

7. Morrison TE. Reemergence of chikungunya virus. $J$. Virol. 88(20), 11644-11647 (2014).
8. CDC - Centers for Disease Control and Prevention. Countries and territories where chikungunya cases have been reported. Chikungunya Virus: Geographic Distribution. https://www.cdc.gov/chikungunya/geo/ index.html. Published 2018.

9. Kraemer MUG, Sinka ME, Duda KA et al. The global distribution of the arbovirus vectors Aedes aegypti and Aedes albopictus. Elife. 4, e08347 (2015).

10. Rodríguez-Morales AJ, Cardona-Ospina JA, UrbanoGarzón FS et al. Prevalence of Post-Chikungunya Infection Chronic Inflammatory Arthritis: A Systematic Review and Meta-Analysis. Arthritis. Care. Res. 68(12), 1849-1858 (2016).

11. Chang AY, Encinales L, Porras A et al. Frequency of Chronic Joint Pain Following Chikungunya Virus Infection: A Colombian Cohort Study. Arthritis. Rheumatol. 70(4), 578-584 (2018).

12. Essackjee K, Goorah S, Ramchurn SK et al. Prevalence of and risk factors for chronic arthralgia and rheumatoid-like polyarthritis more than 2 years after infection with chikungunya virus. Postgrad. Med. J. 89(1054), 440-447 (2013).

13. van Aalst M, Nelen CM, Goorhuis A et al. Long-term sequelae of chikungunya virus disease: A systematic review. Travel. Med. Infect. Dis. 15, 8-22 (2017).

14. Gérardin P, Fianu A, Michault A et al. Predictors of Chikungunya rheumatism: a prognostic survey ancillary to the TELECHIK cohort study. Arthritis. Res. Ther. 15(1), R9 (2013).

15. Murillo-Zamora E, Mendoza-Cano O, TrujilloHernández B et al. Persistent arthralgia and related risks factors in laboratory-confirmed cases of Chikungunya virus infection in Mexico. Rev. Panam. Salud. Publica. 41: e72 (2017).

16. Ramachandran V, Kaur P, Kanagasabai K et al. Persistent arthralgia among Chikungunya patients and associated risk factors in Chennai, South India. J. Postgrad. Med. 60(1), 3-6 (2014). 